\title{
Endogenous Formaldehyde Does Not Produce Detectable DNA-Protein Crosslinks in Rat Liver*
}

\author{
WERNER K. LUTZ \\ Institute of Toxicology, ETH and University of Zürich, $\mathrm{CH}-8603$ Schwerzenbach, Switzerland
}

\begin{abstract}
Formaldehyde is an electrophilic molecule able to crosslink DNA and protein. It has been found to induce tumors in the nasal epithelium in rodents. The safety margin between the maximum tolerated FA concentration in the work place and the concentration found to be tumorigenic in animal studies is very small. Because FA is produced endogenously as a result of a variety of oxidative demethylations, the assessment of the tumor risk from exogenous FA exposure has to be related quantitatively to the level of DNA-protein crosslinks induced by endogenous FA generation. It is reported here that the high level of endogenous FA formed in the liver after a large dose of methanol or of aminopyrine did not lead to any observable increase in DNA-protein crosslinks. Using positive and negative control data from in vitro incubations of liver homogenate with FA or methanol it is estimated that the endogenous level of DNA damage in the liver must be more than three orders of magnitude below the damage observed at tumorigenic concentrations for the rat nose. The fact that FA is formed endogenously cannot, therefore, be used to claim that exogenous FA merely leads to a negligible increase in DNA damage.
\end{abstract}

\section{INTRODUCTION}

Formaldehyde (FA), $\mathrm{H}_{2} \mathrm{C}=\mathrm{O}$, is an industrial chemical used on a large scale for polymer production, disinfection, and conservation. It is an electrophilic chemical and is able to crosslink molecules containing amino groups. DNA-protein crosslinks induced by FA can be detected by an increased migration of DNA into an interfacial band when an aqueous chromatin preparation or organ homogenate is extracted with immiscible lipophilic solvents. Casanova-Schmitz and Heck (2) showed that the yield of interfacial DNA (IF-DNA) significantly increases after exposing rats to $6 \mathrm{ppm} F A$ twice for 6 hours. FA has been found to be mutagenic in many test systems (1). It was therefore not surprising that FA was found to be carcinogenic in bioassays with rodents. FA was tested in rats by inhalation for 6 hours daily, 5 days per week, for 2 years at $0,2,5.6$, and $14.3 \mathrm{ppm}$. Squamous cell carcinomas were induced in the nasal cavity in $0 / 232,0 / 236,2 / 235$, and $103 / 232$ animals, respectively (4). The maximum allowed concentration in the work place (MAK value) in many countries is $1 \mathrm{ppm}$. Because of this small safety margin, it is of prime importance to define a correct dose-response relationship (5). Another factor which must be considered for a risk

* Presented at the Third Sardinian International Symposium, October 6-9, 1985 in Cagliari, Italy. assessment is the fact that FA is a physiological intermediate, e.g., in the demethylation of lanosterol during steroid biosynthesis. Another important process leading to intracellular generation of formaldehyde is the degradation of choline, glycine, and serine.

It was the aim of the work presented here to find out how large the endogenous FA level is in comparison with exogenous FA exposures. For this purpose, the level of DNA-protein crosslinks was determined in rat liver under conditions of maximum intracellular FA generation. The results were compared with positive control data from in vitro incubations of liver homogenate with FA and methanol as well as with literature data on crosslinks in the nasal epithelium.

\section{METHODS}

A high level of intracellular FA is generated by zero order oxidation of methanol. The maximum rate of methanol oxidation in the rat is between 24 and $30 \mathrm{mg} / \mathrm{kg} / \mathrm{hr}(6)$. Under the assumption that the liver is the main organ for methanol oxidation about $0.1 \mathrm{mmol} F A$ can be formed per $\mathrm{g}$ liver in 4 hours.

Male Sprague-Dawley rats received $1 \mathrm{~g}$ methanol per $\mathrm{kg}$ by gavage. One group was given additionally $0.6 \mathrm{~g} / \mathrm{kg}$ disulfiram, shown in humans to inhibit acetaldehyde oxidation, with the idea that higher steady-state levels of FA might be achieved. After 
TABLE 1.-Isolation of AQ-DNA and of IF-DNA from rat liver 4 hours after oral administration of methanol and disulfiram. ${ }^{a}$

\begin{tabular}{|c|c|c|c|}
\hline Treatment $^{b}$ & Methanol & $\begin{array}{c}\text { Methanol + } \\
\text { disulfiram }\end{array}$ & Control \\
\hline AQ-DNA $(\mu \mathrm{g})$ & $450 \pm 80$ & $390 \pm 20$ & $480 \pm 20$ \\
\hline IF-DNA $(\mu \mathrm{g})$ & $5.2 \pm 0.8$ & $4.8 \pm 2.1$ & $5.9 \pm 2.1$ \\
\hline $\begin{array}{l}\% \text { IF-DNA in } \\
\text { total }\end{array}$ & $1.1 \pm 0.3$ & $1.2 \pm 0.5$ & $1.2 \pm 0.4$ \\
\hline
\end{tabular}

${ }^{a}$ Disulfiram $0.6 \mathrm{~g} / \mathrm{kg}$ given $16 \mathrm{hr}$ before methanol $(1 \mathrm{~g} / \mathrm{kg})$ administration.

${ }^{b}$ Values represent mean \pm standard deviation of three isolations.

4 hours, the animals received ethanol by gavage to inhibit further methanol oxidation and were killed to isolate the chromatin fraction from the liver. DNA was then recovered from the aqueous phase (=AQDNA) and from the interface. The latter fraction was treated with proteinase $\mathrm{K}$ after which the DNA migrated into the aqueous phase. The yield of DNA in the two different layers was expressed in terms of the total.

Methanol oxidation in the rat is mediated primarily by catalase in peroxisomes. Demethylation of lanosterol is dependent on cytochrome P 450dependent oxygenases of the endoplasmic reticulum. To study whether the different subcellular localization of FA production was important for the subsequent interaction in the nucleus, the same type of experiment was performed with aminopyrine (AP) instead of methanol as FA precursor.

In addition, the formation of DNA-protein adducts was investigated in vitro using liver homogenate from male SD rats incubated for 4 hours with different concentrations of FA or methanol. Again, the distribution of DNA into the various layers was determined as a measure for crosslink formation. In one additional set of experiments, intact nuclei were isolated from the homogenate after a half-hour incubation with FA in order to estimate the protective power of the nuclear compartment.

\section{RESUlts}

Table I shows that the yield of IF-DNA in the liver was not different from control values after administration of methanol or of methanol plus disulfiram to adult male rats. The same negative result was seen in a second set of experiments where methanol or aminopyrine had been given (data not shown).

Table II shows the results of an in vitro experiment with FA and liver homogenate. It can be seen that even the lowest concentration of FA tested in this system, $0.1 \mathrm{mM}$, resulted in an observable reduction of the DNA in the aqueous phase. Additional ex-
TABLE II. - Yield of AQ-DNA, 4 hours after incubation of rat liver homogenate with formaldehyde. ${ }^{\circ}$

\begin{tabular}{lcccc}
\hline \hline & \multicolumn{4}{c}{ Formaldehyde concentration (mM) } \\
\cline { 2 - 5 } & 0 & 0.1 & 0.5 & 1.0 \\
\hline AQ-DNA $(\mu \mathrm{g})$ & $142 \pm 6$ & $117 \pm 6$ & $61 \pm 11$ & $33 \pm 5$ \\
$\%$ of control & 100 & 82 & 43 & 23 \\
\hline a Values represent mean \pm standard deviation of three exper- \\
iments.
\end{tabular}

periments showed that the remaining DNA was recovered from the interface after treatment with proteinase $\mathrm{K}$ (data not shown). The sum remained constant.

From in vivo experiments not included here, we had an indication that FA production and crosslinking of DNA with protein continued in liver homogenate after death if methanol was still present in the liver at the time of sacrifice. This finding prompted us to use methanol also in in vitro incubations so that a comparison with the effects obtained with FA could be made. Table III shows that methanol produced an increased level of crosslink formation up to a concentration of about $0.5 \mathrm{~mm}$; at this level the effects were comparable with those induced by FA. No further increase could be generated with higher methanol concentrations. It can therefore be assumed that in liver homogenate 0.5 mM methanol can be oxidized to a steady-state concentration of FA. It will be discussed later how many times more effectively the intact animal can metabolize methanol.

The minimum effective methanol concentration in liver homogenate required to generate a detectable increase in DNA-protein crosslinks is $0.01 \mathrm{~mm}$ (Table III). Therefore, FA-induced crosslinks could be observed at concentrations that are at least 50 times below the steady-state concentration of FA produced by methanol in liver homogenate.

For the attempted comparison of in vivo and in vitro data, an additional factor had to be taken into account. In vivo, the DNA is separated from the site of FA formation by an intact nucleus, whereas in vitro, the homogenization procedure in part disrupts the nuclear membrane so that some DNA is in direct contact with the FA. Extranuclear DNA might therefore exhibit a higher level of crosslink formation. The protection of DNA from FA by the nuclear compartment was estimated on the basis of the following experiment. Liver homogenate was incubated as usual with FA. Then intact nuclei were prepared by sucrose gradient centrifugation and were used for the isolation of DNA. A 5 mM FA concentration was required for 30 minutes to bring 10 percent of the DNA into the interface (Table IV), whereas $0.1 \mathrm{~mm}$ during 4 hours was sufficient for a 
TABLE III. - Yield of AQ-DNA, 4 hours after incubation of rat liver homogenate with methanol. ${ }^{\circ}$

\begin{tabular}{lccccccccc}
\hline & \multicolumn{7}{c}{ Methanol concentrations (mM) } \\
\cline { 2 - 10 } & 0 & 0.01 & 0.05 & 0.1 & 0.5 & 1.0 & 5.0 & 10.0 \\
\hline AQ-DNA ( $\mu \mathrm{g})$ & $213 \pm 13$ & $189 \pm 7$ & $176 \pm 30$ & $156 \pm 2$ & $50 \pm 7$ & $45 \pm 8$ & $28 \pm 1$ & $57 \pm 2$ \\
$\%$ of control & 100 & 89 & 83 & 73 & 23 & 21 & 13 & 27 \\
\hline
\end{tabular}

a Values represent mean \pm standard deviation of two experiments.

similar effect in DNA isolated from the crude homogenate (Table II). A protection factor of about 10 can be derived from these data for DNA in intact nuclei.

\section{Discussion}

Casanova-Schmitz and Heck (2) have shown that a significant increase in DNA-protein crosslinks is produced in rat nasal epithelium after inhalation of $6 \mathrm{ppm}$ FA, i.e., a concentration that leads to a borderline increase in tumor incidence after life-span treatment. This means that an increased yield of IFDNA is detectable in situations that are tumorigenic for the animal. On the other hand, in the liver, the main site of endogenous FA production, treatment of rats with methanol or aminopyrine did not result in a detectable increase in DNA-protein crosslinks. An attempt is made below to compare these two situations quantitatively and to relate the data to the level of endogenous FA production. For this purpose, three steps were taken.

First, the rate of endogenous FA generation by cholesterol biosynthesis and by choline degradation was compared with the rate of FA formed by the oxidation of methanol. Rats on a diet free of cholesterol produce about $50 \mathrm{mg}$ cholesterol per $\mathrm{kg}$ of body weight per day (3). Taken that each molecule of lanosterol provides 3 molecules of formaldehyde and that this biosynthesis is performed in $40 \mathrm{~g}$ liver per $\mathrm{kg}$ of body weight, an FA production of 1.6 $\mu \mathrm{mol} / \mathrm{g}$ liver $/ 4 \mathrm{hr}$ can be calculated. Methanol on a zero order kinetics produces on the order of $94 \mu \mathrm{mol}$ $\mathrm{FA} / \mathrm{g}$ liver in 4 hours. The difference, therefore, is a factor of more than 60 .

TABLE IV. - Incubation of rat liver homogenate with formaldehyde. Isolation of AQ- and IF-DNA from nuclei.

\begin{tabular}{lrrrr}
\hline & \multicolumn{4}{c}{ Formaldehyde concentration (mM) } \\
\cline { 2 - 5 } & \multicolumn{1}{c}{0} & \multicolumn{1}{c}{1} & \multicolumn{1}{c}{3} & \multicolumn{1}{c}{5} \\
\hline AQ-DNA $(\mu \mathrm{g})$ & 1,265 & 1,209 & 1,163 & 1,081 \\
IF-DNA $(\mu \mathrm{g})$ & 16 & 29 & 62 & 123 \\
$\begin{array}{l}\text { Sum AQ + IF- } \\
\text { DNA }(\mu \mathrm{g})\end{array}$ & 1,281 & 1,238 & 1,225 & 1,204 \\
$\begin{array}{l}\text { \% IF-DNA of } \\
\text { total }\end{array}$ & 1.2 & 2.3 & 5.1 & 11.2 \\
\hline
\end{tabular}

Second, the zero order rate of methanol oxidation in vivo was compared with the maximum rate in the homogenate. The methanol concentration in vitro, which resulted in a maximum possible $\mathrm{FA}$ production, was $0.5 \mathrm{~mm}$. Under the given experimental conditions, this corresponded to an FA production of $4 \mu \mathrm{mol}$ FA per $\mathrm{g}$ liver during that 4 -hour incubation. This also means that the in vivo formation of formaldehyde from methanol was faster than in vitro by a factor of more than $20(94: 4)$.

Third, the zero order methanol oxidation in vitro was compared with the methanol concentration, which gave rise to a detectable increase in DNAprotein crosslinks. The limit of detection for DNAprotein crosslinks in the in vitro incubation was at $0.01 \mathrm{~mm}$, i.e., at least 50-times below the FA concentration produced by zero order methanol oxidation in vitro.

One factor operating in the opposite direction comes from the intranuclear protection of the in vivo situation. Here, a value of $1 / 10$ must be taken into account. Combining all four factors, it can be concluded that the formation of FA by maximum steroid biosynthesis is $60 \times 20 \times 50 \times 0.1$, or 6,000 fold below that level of DNA-protein crosslinks, which can be observed in a situation of increased tumor formation.

This quantitative analysis must be viewed with due caution because the rate of DNA repair has been assumed to be equal in the three test systems. Also, only the liver has been investigated as the most important tissue for both oxidative demethylations and methanol oxidation. For other types of cells, it would be important to know the relative rates of production and removal of FA. FA is oxidized to formic acid and carbon dioxide, and the respective enzyme activities seem to govern the local concentration of FA at the critical target macromolecules. The respective enzyme activities are cell-type specific, so what holds for the liver cannot be applied directly to other tissues.

The above quantitative estimation is based upon a maximum possible cholesterol biosynthesis as a source of endogenous FA. With a diet containing cholesterol, the endogenous formation of FA will be lower. On the other hand, FA generation by degradation of choline, serine, and glycine is of the same 
order as estimated above for maximum steroid biosynthesis (7). Therefore no large deviation from the above assumptions for the endogenous FA level in liver are expected.

The overall span of a factor of 6,000 is quite remarkable. Small deviations in one or the other of the estimations required for the above evaluation are therefore unlikely to lead to an entirely different picture. The fact that FA is formed endogenously cannot, therefore, be used to claim that exogenous FA merely leads to a negligible increase in DNA damage.

\section{ACKNOWLEDGMENTS}

This presentation includes the analysis of data elaborated by Dr. U. Minini for his Ph.D. thesis. Supported by grant No. 3.842-0.81 from the Swiss National Science Foundation.

\section{REFERENCES}

1. Auerbach C, Moutschen-Dahmen M, and Moutschen $J$ (1977). Genetic and cytogenetical effects of formal- dehyde and related compounds. Mutat. Res. 39: 317362.

2. Casanova-Schmitz $M$ and Heck Hd'A (1983). Effects of formaldehyde exposure on the extractability of DNA from proteins in the rat nasal mucosa. Toxicol. Appl. Pharmacol. 70: 121-132.

3. Kelley JJ and Tsai AC (1978). Effect of pectin, gum arabic and agar on cholesterol absorption, synthesis and turnover in rats. J. Nutr. 108: 630-639.

4. Swenberg JA, Kerns WD, Mitchell RI, Gralla EJ, and Pavkov KL (1980). Induction of squamous cell carcinomas of the rat nasal cavity by inhalation exposure to formaldehyde vapor. Cancer Res. 40: 3398-3402.

5. Swenberg JA, Barrow CS, Boreiko CJ, Heck Hd'A, Levine RJ, Morgan KT, and Starr TB (1983). Nonlinear biological responses to formaldehyde and their implications for carcinogenic risk assessment. Carcinogenesis 4: 945-952.

6. Tephly TR, Parks RE Jr, and Mannering GJ (1964). Methanol metabolism in the rat. J. Pharmacol. Exp. Therap. 143: 292-300.

7. Zeisel SH (1981). Dietary choline: Biochemistry, physiology and pharmacology. Ann. Rev. Nutr. 1: 95-121. 